\title{
INHIBITION OF $\alpha$-MSH SECRETION IS ASSOCIATED WITH INCREASED CYCLIC- AMP EGRESS FROM THE NEUROINTERMEDIATE LOBE OF XENOPUS LAEVIS
}

\author{
Department of Cellular Animal Physiology, Nijmegen Institute for Neurosciences, \\ University of Nijmegen, Toernooiveld 1, 6525 ED Nijmegen, The Netherlands
}

(Reccived in final form October 16, 1995)

\begin{abstract}
$\underline{\text { Summary }}$
Cyclic-AMP is known to be released from cells and tissues and the amounts released have been reported to reflect intracellular cAMP levels. To measure cAMP release the phosphodiesterase inhibitor IBMX is often used to increase the amount of cAMP to a detectable level. Using this method to follow cAMP dynamics of melanotrope cells in the neurointermediate pituitary lobe of the amphibian Xenopus laevis we show that the $\alpha$-MSH secreto-inhibitors baclofen (GABA $A_{B}$ receptor agonist) and dopamine inhibit cAMP release, confirming the idea that these factors inhibit $\alpha-\mathrm{MSH}$ secretion by reducing adenylyl cyclase activity. Using a sensitive cAMP radioimmunoassay we were able to measure cAMP release from Xenopus neurointermediate lobes in the absence of IBMX. Both baclofen and dopamine appeared to inhibit $\alpha$-MSH secretion but strongly stimulated the release of cAMP. This indicates that the extracellular cAMP level is not a reliable parameter to measure the intracellular cAMP level in the absence of IBMX. The data furthermore suggest that cAMP release is a physiologically regulated process, which might be involved in lowering intracellular cAMP levels associated with a cellular secretory compartment. No apparent differences could be found in the lobe content of cAMP at the termination of secreto-inhibitor treatment, leading to the idea that the cAMP compartment associated with secretion is small relative to the total amount of cAMP present in the lobe.
\end{abstract}

Key Words: $\alpha$-melanocyte-stimulating hormone, cAMP, dopamine, GABA

The melanotrope cells in the neurointermediate lobe of the amphibian Xenopus laevis produce and secrete various proopiomelanocortin-derived bioactive peptides, including melanophore-stimulating hormone ( $\alpha-\mathrm{MSH})(1)$. This peptide, which is released in animals that are kept on a black background, stimulates the dispersion of pigment in the dermal melanophores thus causing darkening of the skin (2). The secretion of $\alpha$-MSH from the melanotropes is under complex stimulatory and inhibitory control: thyrotropin-releasing hormone (TRH) and corticotropin- 
releasing hormone (CRH) stimulate secretion while $\gamma$-aminobulyric acid (GABA), dopamine and neuropeptide $\mathrm{Y}$ are known inhibitors of $\alpha$-MSH release.

Various studies have indicated that regulation of cyclic adenosine-3',5'-monophosphate (cAMP) production plays an important role in mediating signal transduction in the Xenopus melanotropes and is especially involved in the inhibition of $\alpha$-MSH secretion by GABA via a $\mathrm{GABA}_{\mathrm{B}}$ receptor and by dopamine via a dopamine $\mathrm{D}_{2}$ receptor $(3,4)$. It has also been shown that these cells, like many other cell types, release cAMP into the extracellular space $(5,6)$. The amount of cAMP released from Xenopus melanotrope cells is suggested to be proportional to the intracellular cAMP concentration (5). Such a relationship between extracellular and intracellular cAMP levels is assumed to be a general phenomenon (7).

In many studies on the intracellular cAMP concentration isobutyl methylxanthine (IBMX) is applied because this inhibitor of phosphodiesterase enhances extracellular cAMP concentrations to such a degree that they can be readily determined. To get a better insight into the relationship between intracellular cAMP concentration and cAMP release from the Xenopus neurointermediate lobe we have examined intracellular and extracellular cAMP levels in the presence and absence of IBMX using a sensitive radioimmunoassay. The results indicate that inhibition of $\alpha$-MSH by baclofen and dopamine is concomitant with a strong stimulation of cAMP release from the neurointermediate lobe, questioning the concept of proportionality between intracellular and extracellular cAMP levels.

\section{Methods}

\section{Animals}

Adult Xenopus laevis were bred in our aquatic laboratory facility and adapted to a black background for four weeks prior to the experiments, under continuous illumination, at $22{ }^{\circ} \mathrm{C}$.

\section{Superfusion}

Neurointermediate lobes were dissected and transferred to a superfusion system with four chambers, each chamber holding one lobe on a filter. The superfusion medium contained $112 \mathrm{mM}$ $\mathrm{NaCl}, 2 \mathrm{mM} \mathrm{KCl}, 15 \mathrm{mM}$ HEPES (pH 7.4, carbogen-aerated), $0.03 \%$ bovine serum albumin (fraction V, Sigma, St. Louis, MO, U.S.A.), $0.2 \%$ glucose and $1 \mathrm{mg} / \mathrm{l}$ ascorbic acid. Flow rate was $1.6 \mathrm{ml} / \mathrm{h}$ and fractions were collected at $15 \mathrm{~min}$ intervals for radioimmunoassays of cAMP and $\alpha$ $\mathrm{MSH}$. The receptor agonists baclofen (Ciba-Geigy, Basel, Switzerland) and dopamine (Sigma) were added in various concentrations to the superfusion medium. In some experiments $0.5 \mathrm{mM}$ isobutyl methylxanthine (IBMX; Sigma) was present in the medium. After superfusion each lobe was homogenized in $0.1 \mathrm{~N} \mathrm{HCl}$ and freeze-dried. Subsequently, the residue was supplied with $200 \mu \mathrm{l}$ superfusion medium and cAMP was determined in aliquots of 10,20 and $40 \mu \mathrm{l}$, made up to 100 $\mu \mathrm{l}$ with superfusion medium, with the radioimmunoassay for cAMP.

\section{Radioimmunoassays}

The radioimmunoassay for $\alpha$-MSH was applied as described previously ( 8 ). The cAMP contents of duplicate $100 \mu \mathrm{l}$ aliquots of each fraction were estimated by radioimmunoassay in glass tubes, essentially according to 9,10 . Acetylation was performed by adding $5 \mu \mathrm{l}$ of acetic anhydride and triethanolamine (v/v 1:2). Then $100 \mu \mathrm{l}$ anti-cAMP serum, purchased from Dr J.C. Stoof (Dept. of Neurology, Medical Faculty, Free University, Amsterdam, The Netherlands) and $100 \mu$ l sodium acetate buffer ( $\mathrm{pH} 6.3$ ) containing $0.5 \%$ bovine serum albumin and $0.2 \%$ sodium azide were added. 
${ }^{125}$ I-cAMP was produced by the chloramine-T method (11) and purified according to our standard procedure for labeling of $\alpha$-MSH (12). As a standard, non-acetylated cAMP of Amersham (Little Chalfont, U.K.) was used. Bound and free ${ }^{125} \mathrm{I}$-cAMP were separated by polyethylene glycol/henn egg albumin precipitation. Sensitivity of the assay was 2 fimol cAMP per sample.

\section{Calculations and statistics}

In the figures $\alpha$-MSH secretory data are shown as mean $(n=4)$ with standard error of the mean (SEM; vertical bars) of percent basal release. The $100 \%$ basal release was defined as the mean amount of $\alpha$-MSH measured in the three superfusion fractions immediately preceding the first treatment with a receptor agonist. Cyclic AMP levels are means of 4 samples per time point. Lobe contents were statistically analyzed with one-way analysis of variance $(\alpha=5 \%)(13)$ followed by Duncan's multiple range test (see 14). The analysis was preceded by tests for the joint assessment of normality (15) and the homogeneity of variance (Bartlett's test, see 13).

\section{$\underline{\text { Results and Discussion }}$}

First we established the effects of the inhibitory neural factors on $\alpha$-MSH release and on the intracellular and extracellular concentrations of cAMP, in the presence of IBMX. Baclofen induced a decrease in cAMP contents of the neurointermediate lobe by about $30 \%$ (Fig. 1a) and a decrease in $\alpha$-MSH release by $20 \%$ (Fig. 2a). Similarly, dopamine reduced both intracellular cAMP and $\alpha$ MSH release, by $50 \%$ and $70 \%$, respectively (Figs. 1a, 2b). These data confirm the idea that GABA and dopamine reduce $\alpha$-MSH release by lowering the intracellular cAMP level in the melanotrope cells (6). As to the release of cAMP, both baclofen and dopamine inhibited this process, namely by about $40 \%$ and $50 \%$, respectively (Figs $2 \mathrm{c}, 2 \mathrm{~d}$ ). This observation fits in with the common assumption that therc is a fixcd proportional relationship between intracellular and extracellular cAMP concentrations (7).

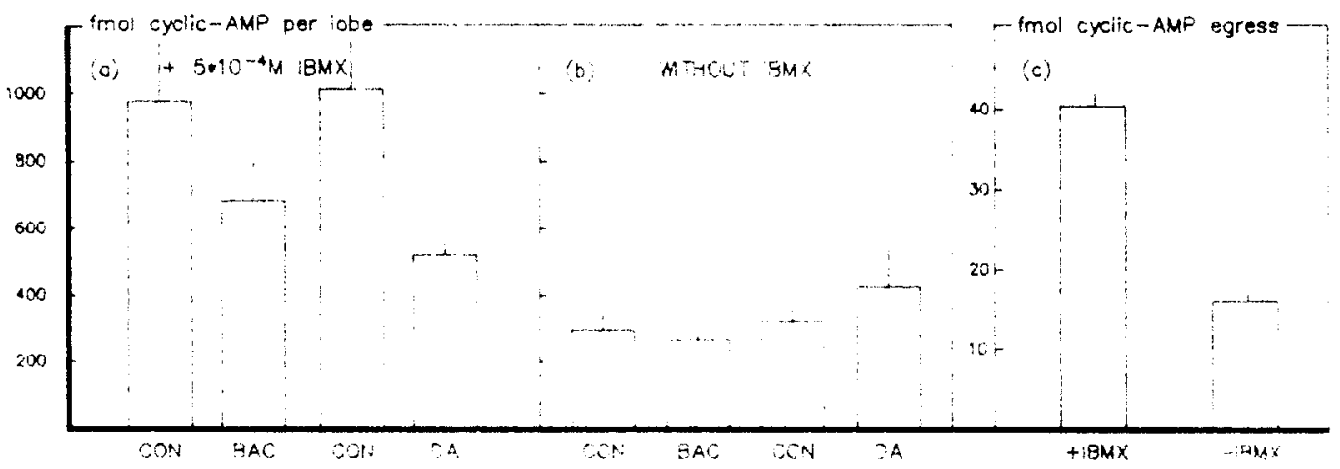

FIG. 1

Lobe contents of CAMP in the presence of IBMX (a) and without the phosphodiesterase inhibitor (b). The contents were at termination of the superfusion determined in the same lobes as used in the Figs. 2 and 3a-d. Error bars indicate + SEM $(n=4)$. In (c) medium contents of cAMP are represented with and without IBMX $(n=8)$. 
Omitting IBMX from control media resulted into a decrease of about 2.5 times in the intracellular (Fig. 1b) and extracellular levels of cAMP (Fig. 1c). When lobes were treated with baclofen or dopamine in the absence of IBMX, $\alpha$-MSH release was still clearly reduced compared to control lobes $(60 \%$ and $50 \%$, respectively; Fig. 3a,b), but no significant change was noted with respect to the intracellular cAMP concentration (Fig. 1b). Even more striking was that under these conditions the extracellular cAMP concentration was strongly elevated, with maximum increases from 2 up to 7 times (Fig. 3c,d, 4). Full stimulation was reached within 15-30 min and appeared to be completely reversed after removal of the inhibitor (Fig. 4). These increases in extracellular cAMP proved to be significant ( $\mathrm{P}<=0.05$ ) and reproducible ( 4 independent experiments) and we therefore conclude that in the absence of IBMX, the degree of cAMP release is not proportional

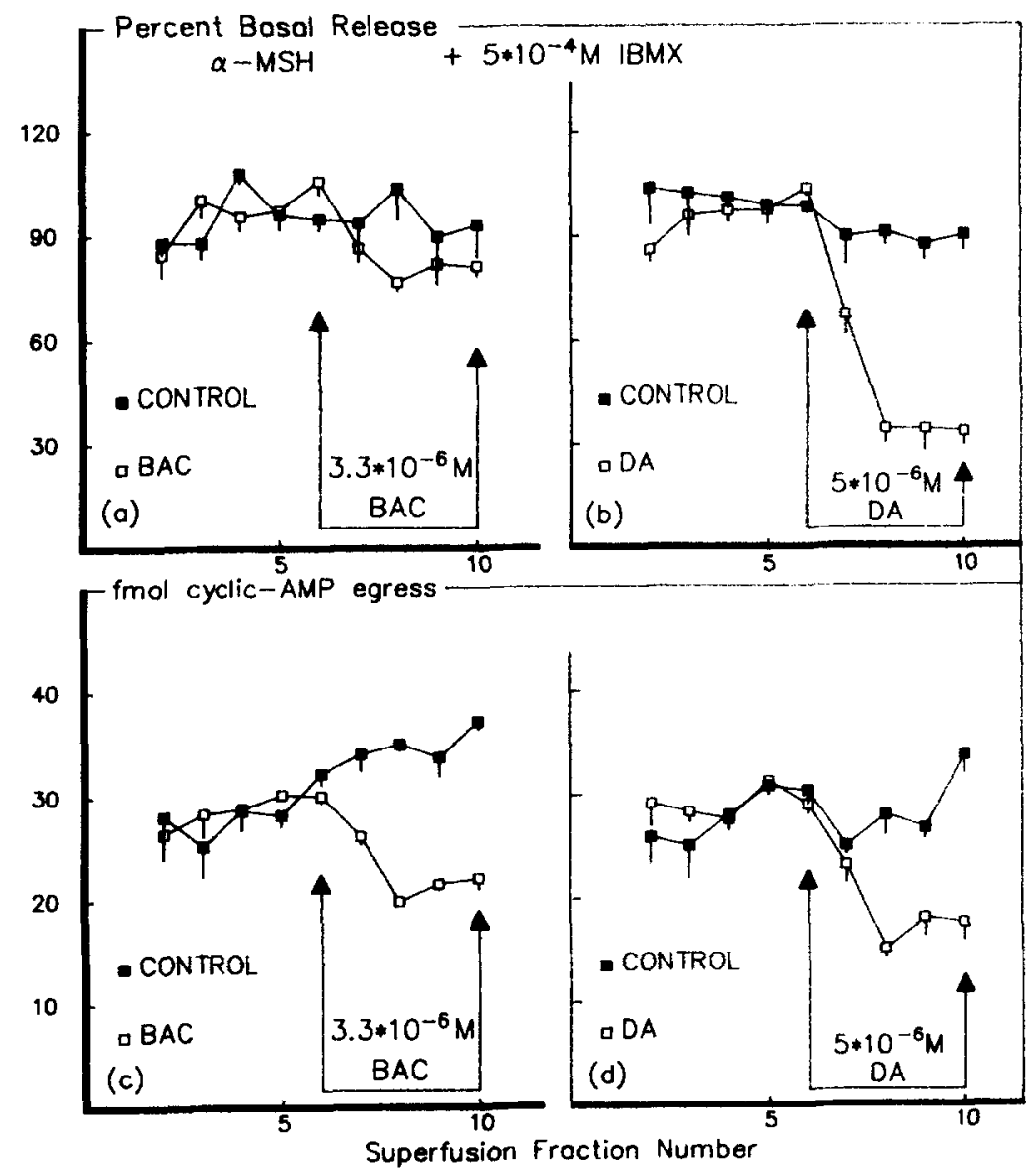

FIG. 2

Release of immunoreactive $\alpha-\mathrm{MSH}$ and cAMP egress from superfused neurointermediate lobes of Xenopus laevis in the presence of IBMX. Arrows represent the periods during which baclofen (BAC) or dopamine (DA) were present. In (c) and (d) egress of cAMP from the same lobes as in (a) and (b) is represented. Error bars indicate -SEM. 


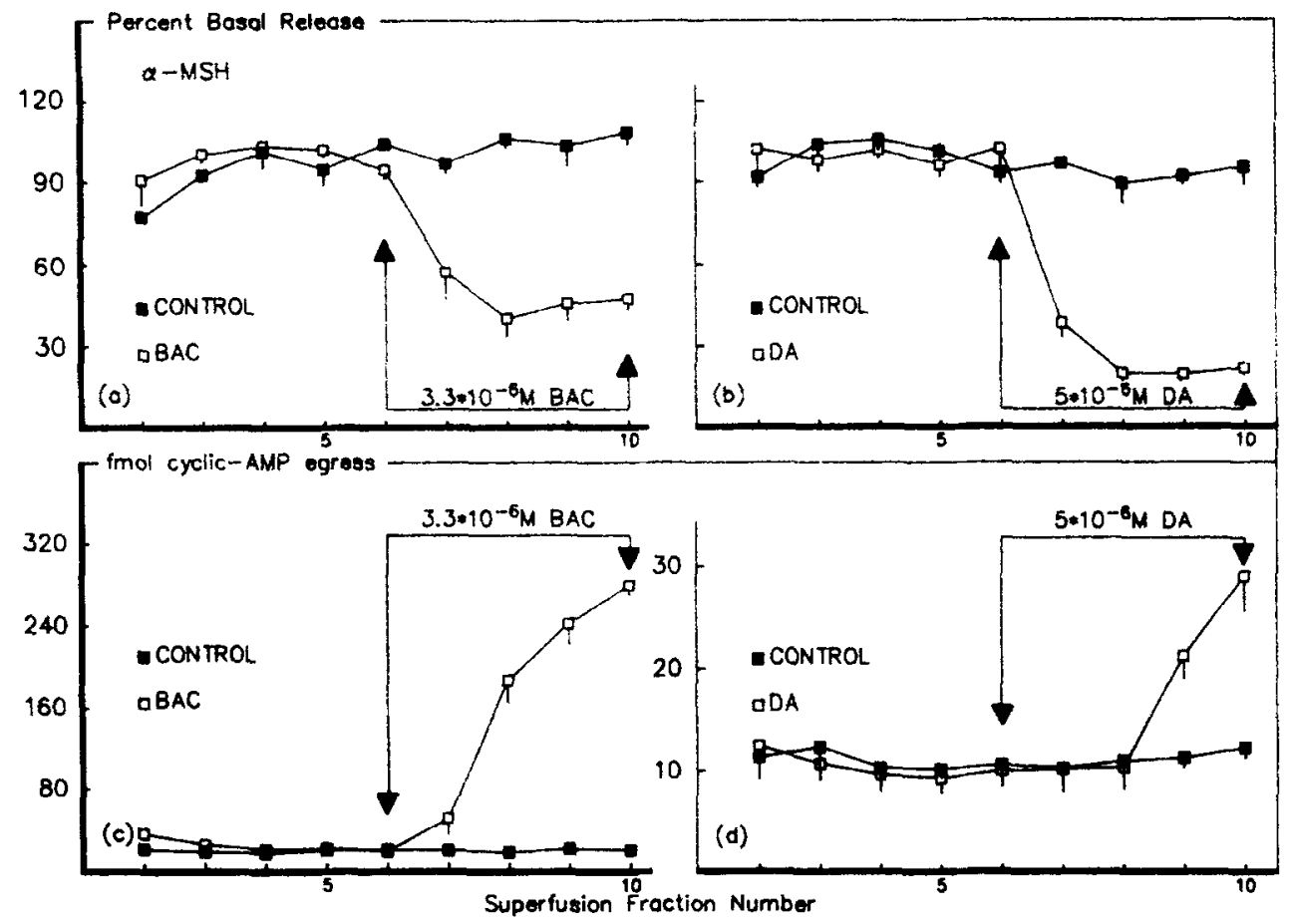

FIG. 3

Release of immunoreactive $\alpha-\mathrm{MSH}$ and cAMP egress from superfused neurointermediate lobes of Xenopus laevis without IBMX. Arrows represent the periods during which baclofen (BAC) or dopamine (DA) were present. In (c) and (d) egress of cAMP from the same lobes as in (a) and (b) is represented.

to the cAMP level within the neurointermediate lobe. We assume that the common observation of proportionality between intracellular and extracellular cAMP levels may be due in at least a number of cases to the use of IBMX that inhibits intracellular breakdown of cAMP. Consequently, it should be strongly questioned whether under physiological conditions (i.e., in the absence of IBMX), the extracellular cAMP concentration is a reliable parameter to assess the intracellular concentration of cAMP.

Concerning our studies in the absence of IBMX, we have to consider how baclofen and dopamine inhibited $\alpha$-MSH release. In view of the strong inhibition of $\alpha-\mathrm{MSH}$ release by these factors (this study) and the fact that the cAMP-analogue 8-bromo-cAMP is able to abolish baclofen-inhibited $\alpha$-MSH release (3), we conclude that these factors inhibit $\alpha$-MSH secretion by reducing the intracellular level of CAMP (see also 6). However, this raises the question why in this study the intracellular cAMP level does not seem to be affected by baclofen or dopamine treatment. Two explanations can be given. First, it may be that only a slight decrease in the intracellular cAMP level of the melanotrope cell, which might be of transient nature and be undetectable in our experimental approach, is sufficient to lead to the observed drastic (up to $60 \%$ ) reduction in $\alpha$-MSH release. Secondly, it may be that this strong reduction in secretion is the result 


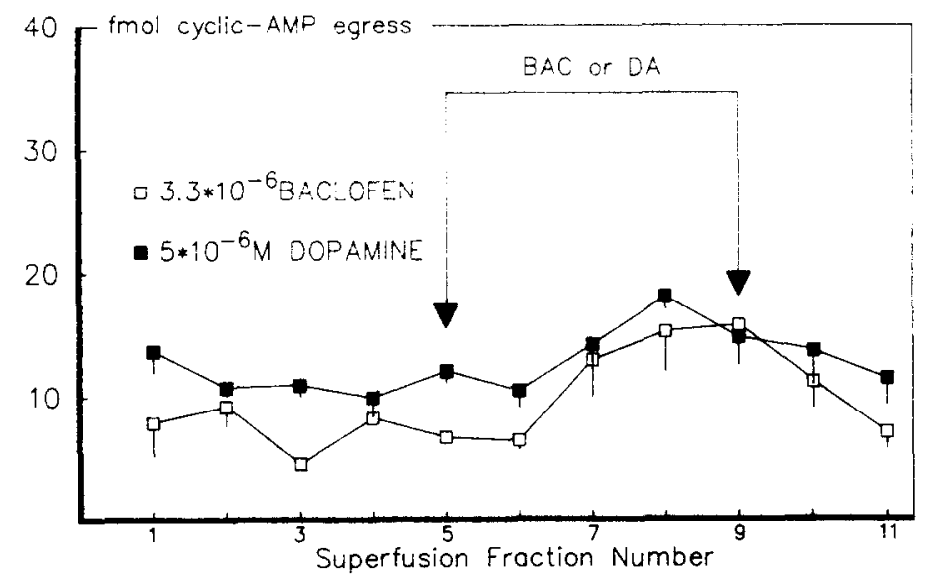

FIG. 4

cAMP egress from superfused neurointermediate lobes of Xenopus laevis without IBMX. Arrows represent the periods during which baclofen (BAC) or dopamine (DA) were present.

of a similar drastic reduction of cAMP, not in the overall neurointermediate lobe, but only in a relatively small compartment within the lobe. This compartment might be a cellular subcompartment within each melanotrope cell, whereas the rest of the cellular cAMP might not be involved in the secretory process. These latter cAMP contents might largely determine the total concentration of cAMP within the lobe and obscure the secretion-related changes in the small compartment. The nature of such compartments is not known. Possibly particular cell organelles like components of the endoplasmatic reticulum are involved. The role of specific cAMP transporters in the plasma membrane also deserves particular attention.

As to the strongly stimulated cAMP release by baclofen and dopamine, this release could reflect a physiological mechanism to lower the intracellular cAMP concentration in the secretionassociated subcompartment of the melanotrope cell, thus leading to a reduced release of $\alpha-\mathrm{MSH}$. The slow increase of cAMP after the addition of the inhibitors BAC and DA (Fig. 3c,d,4) might reflect a slow build up of a sufficient cAMP level in the secretion subcompartment in order to activate the transporter (16).

\section{Acknowledgements}

We wish to thank Mr. P.M.J.M. Cruijsen for technical assistance and Mr. R.J.C. Engels for animal care. This study was supported by grants from the European Community (HCM grant ERBCHRXCT920017) and from INSERM-NWO.

\section{References}

1. B.G. JENKS, B.M.L. VERBURG-VAN KEMENADE and G.J.M. MARTENS, The Melanotropic Peptides: volume 1, M.E. Hadley (ed), 67-83, CRC Press, Boca Raton Florida (1988). 
2. J.T. BAGNARA and M.E. HADLEY, Chromatophores and Color Change, Prentice Hall Inc., Englewood Cliff, New Jersey (1973).

3. H.J. LEENDERS, H.P. DE KONING, S.P. PONTEN, B.G. JENKS and E.W. ROUBOS, Life Sci. $\underline{52}$ 1969-1975 (1993).

4. W.J.J.M. SCHEENEN, B.G. JENKS, P.H.G.M. WILLEMS and E.W. ROUBOS, Eur. J. Physiol. 427 244-251 (1994).

5. B.G. JENKS, I.D. VAN ZOEST, H.P. DE KONING, H.J. LEENDERS and E.W. ROUBOS, Life Sci. 48 1633-1637 (1991).

6. H.P. DE KONING, B.G. JENKS, B. HUCHEDÉ and E.W. ROUBOS, Life Sci. 51 16671673 (1992).

7. R. BARBER and R.W. BUTCHER, Adv. Cycl. Nucl. Res. 15 119-138 (1983).

8. I.D. VAN ZOEST, P.S. HEIJMEN, P.M.J.M. CRUIJSEN and B.G. JENKS, Gen. Comp. Endocrinol. 76 19-28 (1989).

9. A.L. STEINER, C.W. PARKER and D.M. KIPNIS, J. Biol. Chem. 247 1106-1113 (1972).

10. G.L. BROOKER, J.F. HARPER, W.L. TERASAKI and R.D. MOYLAN, Adv. Cycl. Nucl. Res. 10 1-33 (1979).

11. W.M. HUNTER and F.C. GREENWOOD, Nature 194 495-496 (1962).

12. H.J. LEENDERS, J.J.W. JANSSENS, H.J.M. THEUNISSEN, B.G. JENKS and A.P. VAN OVERBEEKE, Neuroendocrinology 43 166-174 (1986).

13. C.J. BLISS, Statistics in Biology, volume 1, McGraw-Hill, New York (1967).

14. R.G.D. STEEL and J.H. TORRIE, Principles and Procedures of Statistics, McGraw-Hill, New York (1960).

15. H.H. SHAPIRO and M.B. WILK, Biometrics 52 591-611 (1965).

16. M.J. PATEL, D.M. WYPIJ, D.A. ROSE, T.J. RIMELE and J.S. WISEMAN, J. Pharmacol. Exp. Therap. 273 16-25 (1995). 